\title{
INVESTIGATIONS FOR ENHANCING THE APPLICATION DOMAIN OF FUSED DEPOSITION MODELLING PROCESS
}

\author{
Rupinder Singh $^{1^{*}}$ and Sunpreet Singh ${ }^{2}$ \\ ${ }^{1}$ Production Engineering Department, GNDEC, Ludhiana, India 141006 \\ ${ }^{2}$ Production Engineering Department, GNDEC, Ludhiana, India 141006 \\ *Corresponding author: rupindersingh78@yahoo.com
}

\begin{abstract}
In the recent past, various studies have been reported on the development of in-house fused deposition modelling (FDM) filament, in order to increase the application domain of the process. But hitherto very less have reported on the effect of reinforcement type (such as: $\mathrm{SiC}, \mathrm{Al}_{2} \mathrm{O}_{3}$ and $\mathrm{Fe}$ powder etc.) on the melt flow index (MFI) of the polymer matrix composite (PMC) to be used as FDM filament. In the present research work, an effort has been made to investigate the effect of selected proportions of filler, matrix (nylon-6) and extrusion load on the MFI of reinforced FDM filament. Experimental study was conducted on melt flow indexer (MFIer) as per ASTM-D1238-95 standard and signal to noise ratio was calculated to find out the effect of input process parameters on MFI of hybrid filament. It has been found that proportion of filler in matrix, type of filler material and extrusion load contributed about $16.62 \%, 1.23 \%$ and $76.72 \%$ respectively.
\end{abstract}

Keywords: melt flow index, fused deposition modelling, nylon-6, additive manufacturing.

\section{INTRODUCTION}

The FDM technology (Figure 1) was established in the late 1980's and several series of machines have been developed by various manufacturers till now ${ }^{1}$. The process dispenses two materials; one for building parts and other for supporting the cantilever like features of the $\mathrm{job}^{2}$. Both materials (in form of filament cartridges) are fed into a temperature-controlled extrusion head that heats the material to a semi-liquid state which finally extruded in form of ultra thin layers onto a fixtureless base with high precision ${ }^{3}$. FDM system is programmed in such a way that speed of feeding screws varies with geometrical cross-section of part ${ }^{4}$ Elastomers, Acrylonitrile-Butadiene-Styrene (ABS) and polycarbonates are some of the common examples of FDM materials, and are patented by commercial manufacturers.

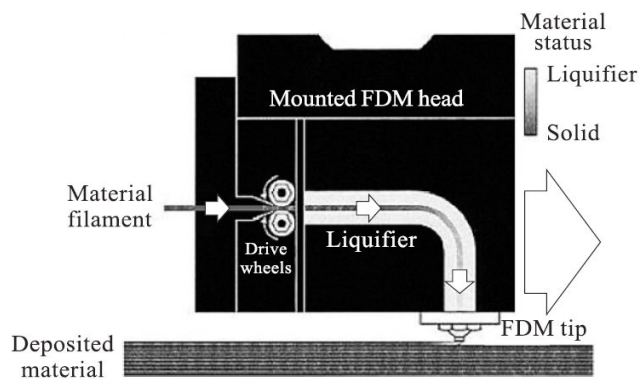

Figure 1. Fused deposition modelling ${ }^{5}$.

In last one decade, research work for the development of cost effective FDM filament was carried out at high pace that helped this setup to increase its applications. Various types of FDM based material including metals, ceramics and composites were developed by various researchers with required size, strength and mechanical properties for different end user applications ${ }^{5}$. Some research work highlighted the feasibility of developing metal matrix composite materials by using the reinforced FDM based pattern in investment casting process ${ }^{5-6}$. Some studies highlighted that in order to develop rapid tooling by using an alternative hybrid FDM filament material, it is mandatory to investigate the flow behaviour of filament material ${ }^{7}$. Generally, the deposition rate of FDM system is affected by various factors like: pressure drop while extrusion, velocity/rpm of feed screw of extrusion and the geometrical dimensions at the exit. The pressure drop along the melt flow highly affects the quantity of force required to push the filament out of the head and directly affects the quality of the product due to variation of road width ${ }^{7}$.

It has been observed from the literature review that there exists a critical need for the development of a cost effective alternative FDM filament material in order to explore the potential applications of this technology in different fields involving: automotive, aerospace, biomedical, consumer, electrical and electronic products. However, very less work has reported on the importance of processing parameters of hybrid filament mixtures on its melt flow index (MFI), as some of the FDM systems do not allow changing their processing conditions. So it is mandatory that the alternatively selected filament material should possess the reasonable match of MFI values with the commercial material (assigned by the manufacturers).

The aim of the present study is to investigate MFI of the selected proportions of material prior to their fabrication in FDM filament form. Further, the effect of processing parameters on MFI has also been studied. For this study $\mathrm{SiC}, \mathrm{Al}_{2} \mathrm{O}_{3}$ and $\mathrm{Fe}$ (all of 125 mesh size) were used as filler and nylon- 6 was used as matrix material. As there were no ASTM/other industrial standards available 
for testing MFI of hybrid mixtures, so the experimenttation was performed as per the ASTM-D1238-95 standard available for the ABS material.

\section{MELT FLOW INDEXER}

Melt flow indexer (MDIer) was used to measure the rate of extrusion of molten resins through a die of a specified length and diameter under prescribed condition of temperature and load. MFIer serves to indicate the uniformity of the flow rate of polymer as made by individual process. The schematic of MFIer is shown in Figure 2 and its different functioning parts are explained as followings ${ }^{7}$ :

The MFIer consisted of a dead weight piston consisting of a thermostatically controlled heated steel cylinder with a die at the lower end.

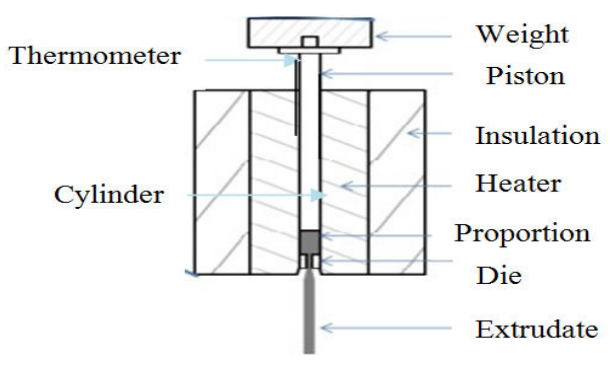

Figure 2. Schematic of MFIer.

All the dimensions of plastometer were made at 18$28^{\circ} \mathrm{C}$ temperature. The steel cylinder is of $50.8 \mathrm{~mm}$ in diameter, $162 \mathrm{~mm}$ in length with a smooth, straight hole and displaced $4.8 \mathrm{~mm}$ from cylinder axis. A $3.2 \mathrm{~mm}$ plate is attached to the bottom of the cylinder to retain the die and hole in this plate, centered under the die and countersunk from below, allows free passage of the extrudate. The die of MFIer was made of tungsten carbide attached at the bottom with an outside diameter that falls freely to the bottom of the $9.5504 \pm 0.0076 \mathrm{~mm}$ diameter hole in the cylinder. The die has a smooth straight bore of $2.0955 \pm 0.0051 \mathrm{~mm}$ in diameter and is $8.000 \pm 0.025 \mathrm{~mm}$ in length.

The bore and its finish are critical to the process and it must free from visible drill or other tool marks and no detectable eccentricity. Further, the piston was made of steel with an insulating burnishing at the top as a barrier to heat transfer from the piston to the weight. The land of the piston is $9.4742 \pm 0.0076 \mathrm{~mm}$ in diameter and $6.35 \pm 0.13 \mathrm{~mm}$ in length. The indexer was equipped with a heater capable of heating the apparatus so that temperature at $10 \mathrm{~mm}$ above the die can be maintained during the test. The cylinder heater are lagged with $38 \mathrm{~mm}$ of foamed glass insulation and insulating plate $3.2 \mathrm{~mm}$ in thickness is attached to the bottom of the cylinder to minimize heat loss at this point. A thermometer having a range of $4^{\circ} \mathrm{C}$ graduated in $0.2^{\circ} \mathrm{C}$ division was used to indicate temperature and the temperature of material at $10 \mathrm{~mm}$ above the die was calibrated with the reference of platinum resistance temperature sensor inserted in the material $10 \mathrm{~mm}$ above the die.

In the present research work, MFIer (commercially supplied by Shanta Engineering, Pune) was used. The pictorial view of MFIer is shown in Figure 3.

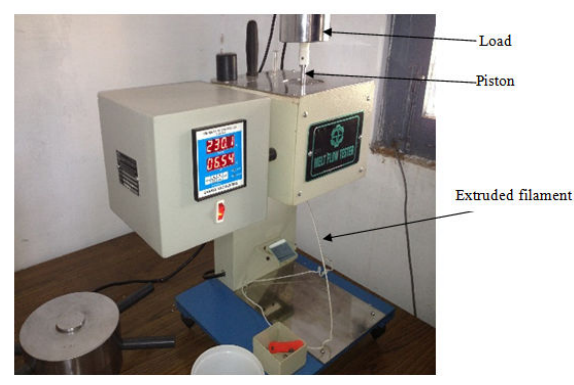

Figure 3. Pictorial view of MFIer.

\section{EXPERIMENTATION}

Initially, the MFI of commercial ABS-P430 FDM material was tested and found to be $2.411 \mathrm{gm} / 10 \mathrm{~min}$ (at $230^{\circ} \mathrm{C}$ and $3.8 \mathrm{~kg}$ load as per ASTM-D1238-95 standard). Therefore, any alternative thermoplastic material with an MFI value approximately equal to $2.411 \mathrm{gm} / 10 \mathrm{~min}$ can be used successfully on existing FDM system without any iteration made on system. For the others having higher or lower values of MFI, it becomes necessary to make some iterations in-term of extrusion temperature, speed of the ram and speed of the rollers. The higher MFI of the PMC will be beneficial for increasing the speed of fabrication. But for achieving high fabrication rate, some iterations in-terms of increasing the ram speed, maintaining the roller speed and extrusion temperature must to incorporate in the FDM system. The MFI of virgin nylon6 matrix was found as $10.60 \mathrm{gm} / 10 \mathrm{~min}$. This plastic matrix material (particle size $4-5 \mathrm{~mm}$ ) was crushed to powder form $(500-800 \mu \mathrm{m})$ using cryogenic grinding. Mixing of powder formed nylon- 6 matrix and $\mathrm{SiC}, \mathrm{Al}_{2} \mathrm{O}_{3}$ and $\mathrm{Fe}$ reinforcements (separately) was carried out through hand mixing process with a flexible stirrer using coconut oil as binder. $\mathrm{SiC}, \mathrm{Al}_{2} \mathrm{O}_{3}$ and $\mathrm{Fe}$ were selected due to their high wear resistance and thermal conductivity. Further, due to the higher electrical conductivity of $\mathrm{Fe}$ reinforced nylon- 6 based FDM filament could have numerous applications in electronic \& communication and electrical sector for fabricating advanced integrated circuits.

The number of control factors with their designations and values at three parametric levels are shown in Table 1. The control log of experimentation is given in Table 2. Each experiment of Table 2 was repeated thrice (as $R^{1}, R^{2}$ and $\mathrm{R}^{3}$ ) for reducing the errors due to human intervention. 
Table 1. Input parameters.

\begin{tabular}{|c|c|c|c|}
$\stackrel{\text { Parameters }}{\longrightarrow}$ & $\begin{array}{c}\text { Type of } \\
\text { filler } \\
\text { (A) }\end{array}$ & $\begin{array}{c}\text { Proportion } \\
\text { of filler in } \\
\text { \% wt. } \\
\text { (B) }\end{array}$ & $\begin{array}{c}\text { Extrusion } \\
\text { load (C), } \\
\text { kg }\end{array}$ \\
\hline 1 & $\mathrm{Al}_{2} \mathrm{O}_{3}$ & 30 & 1.2 \\
\hline 2 & $\mathrm{SiC}$ & 40 & 3.8 \\
\hline 3 & $\mathrm{Fe}$ & 50 & 5 \\
\hline
\end{tabular}

Table 2. Final experimentation.

\begin{tabular}{|c|c|c|c|}
\hline Exp. No. & $\mathbf{A}$ & B & C \\
\hline 1 & $\mathrm{Al}_{2} \mathrm{O}_{3}$ & 30 & 1.2 \\
\hline 2 & $\mathrm{Al}_{2} \mathrm{O}_{3}$ & 40 & 3.8 \\
\hline 3 & $\mathrm{Al}_{2} \mathrm{O}_{3}$ & 50 & 5 \\
\hline 4 & $\mathrm{SiC}$ & 30 & 3.8 \\
\hline 5 & $\mathrm{SiC}$ & 40 & 5 \\
\hline 6 & $\mathrm{SiC}$ & 50 & 1.2 \\
\hline 7 & $\mathrm{Fe}$ & 30 & 5 \\
\hline 8 & $\mathrm{Fe}$ & 40 & 1.2 \\
\hline 9 & $\mathrm{Fe}$ & 50 & 3.8 \\
\hline
\end{tabular}

Systematic steps involved in experimental procedure are given below:

- Weight the quantity of nylon-6 and metallic filler on balancing machine of $0.001 \mathrm{gm}$ accuracy.

- Mix nylon-6 and metallic filler appropriately in presence of paraffin wax unit metallic filler particles sticks to nylon-6 granules.

- $\quad$ Set barrel temperature to $230^{\circ} \mathrm{C}$.

- Insert the mixed proportion of material (about $7 \mathrm{gm}$ each time) into barrel.

- Insert plunger into barrel, place weight as per experimentation and start timer simultaneously.

- Cut and weight the extruded wire.

- Repeat the above steps.

- Clean the barrel, die and plunger with soft cotton.

\section{RESULTS AND DISCUSSION}

The extruded material was weighted on Citizon's CY-220 balancer (having accuracy of $0.001 \mathrm{gm}$. The results for MFI are given in Table 3. The results obtained were optimized at 'larger the better' option as the increase in the speed of deposition will help in reducing the time and cost of prototyping. The signal/noise $(\mathrm{S} / \mathrm{N})$ ratio and sum of square (SS) are calculated using Eq. 1 and 2 respectively. Table 4 shows calculated values of SS and $\mathrm{S} / \mathrm{N}$ ratio for present set of experiments.

$$
\mathrm{S} / \mathrm{N} \text { ratio }=-10 \times \log (\mathrm{SS})
$$

Where 'SS' is Sum of Square calculated from Eq. 2, as:

$$
\mathrm{SS}=(1 /(\mathrm{R} 1 * \mathrm{R} 1)+1 /(\mathrm{R} 2 * \mathrm{R} 2)+1 /(\mathrm{R} 3 * \mathrm{R} 3)) / 3
$$

Table 3. Results of MFI.

\begin{tabular}{|c|c|c|c|c|}
\hline \multirow{2}{*}{ S. No. } & \multicolumn{4}{|c|}{ MFI (gm/10min) } \\
\cline { 2 - 5 } & $\mathbf{R}^{\mathbf{1}}$ & $\mathbf{R}^{\mathbf{2}}$ & $\mathbf{R}^{\mathbf{3}}$ & $\mathbf{A v g .}$ \\
\hline 1 & 1.89 & 1.66 & 1.61 & 1.72 \\
\hline 2 & 3.21 & 3.25 & 3.11 & 3.19 \\
\hline 3 & 3.50 & 3.15 & 3.74 & 3.46 \\
\hline 4 & 4.64 & 3.91 & 4.12 & 4.22 \\
\hline 5 & 7.01 & 6.97 & 6.89 & 6.95 \\
\hline 6 & 1.63 & 1.63 & 1.64 & 1.63 \\
\hline 7 & 6.12 & 6.73 & 6.28 & 6.37 \\
\hline 8 & 2.28 & 2.19 & 2.45 & 2.30 \\
\hline 9 & 6.01 & 5.98 & 6.07 & 6.02 \\
\hline
\end{tabular}

Table 4. SS and $\mathrm{S} / \mathrm{N}$ responses to MFI results.

\begin{tabular}{|c|c|c|}
\hline S. No. & SS & S/N ratio \\
\hline 1 & 0.3428774 & 4.648 \\
\hline 2 & 0.0983712 & 10.071 \\
\hline 3 & 0.0846352 & 10.724 \\
\hline 4 & 0.0569234 & 12.447 \\
\hline 5 & 0.0206664 & 16.847 \\
\hline 6 & 0.3748532 & 4.2614 \\
\hline 7 & 0.0247112 & 16.071 \\
\hline 8 & 0.1891556 & 7.231 \\
\hline 9 & 0.0275967 & 15.591 \\
\hline
\end{tabular}

As per the values of Table 4 , Figure 4 shows the highest value of the $\mathrm{S} / \mathrm{N}$ ratio for MFI w. r. t. to input parameters.

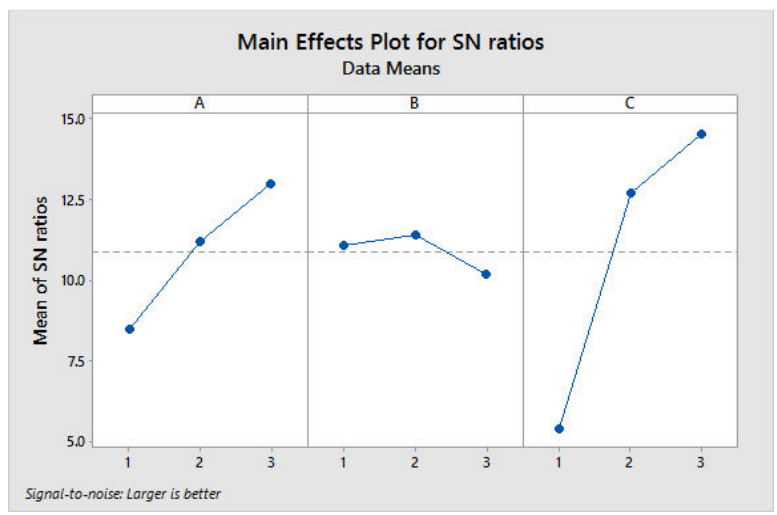

Figure $4 . \mathrm{S} / \mathrm{N}$ response to input parameters.

Figure 4, it has been found that MFI of the hybrid mixture was changed with levels of input parameters. In case of type of filler, the minimum, intermediate and maximum value of MFI was observed with $\mathrm{Al}_{2} \mathrm{O}_{3}, \mathrm{SiC}$ and Fe fillers respectively. The reason behind this trend may be because of the difference in thermal behavior/conductivity of fillers. Basically, the $\mathrm{Al}_{2} \mathrm{O}_{3}, \mathrm{SiC}$ and $\mathrm{Fe}$ have the thermal conductivity of $30 \mathrm{~W} / \mathrm{mk}$, $50 \mathrm{~W} / \mathrm{mk}$ and $80.4 \mathrm{~W} / \mathrm{mk}$ respectively. Due to the difference in their thermal conductivity, $\mathrm{Al}_{2} \mathrm{O}_{3}$ powder 
particles transferred less amount of heat to the nylon- 6 matrix, which resulted into reduced MFI value. Similarly, Fe particles with maximum thermal conductivity have transferred the heat to adjoining nylon-6 matrix and formed a uniform melt of the extrudate possessing an ease in flow-ability. This means that the natural properties of the filler materials play a very significant role for their extrusion behavior which must be taken in consideration while developing an alternative FDM filament.

In case of parameter $\mathrm{B}$, increasing the percentage of filler has reduced the MFI value. One of the obvious reasons behind the trend was the increased viscosity of the melt due to more number of filler percentages. However, this process parameter did not have much contributed in resulting MFI value as the trend is almost a flat line along the central/mean line. Similarly, in case of parameter $\mathrm{C}$ it has been observed that MFI is directly proportional to the extrusion load. More the force load more the extrudate was formed. Response of $\mathrm{S} / \mathrm{N}$ ratio to input parametric levels is given in Table 5. Analysis of variance (see Table 6) has been conducted at $95 \%$ confidence level (error 5\%) shows the maximum contribution of extrusion load in MFI.

Table 5. Response for $\mathrm{S} / \mathrm{N}$ ratio at larger the better.

\begin{tabular}{|c|c|c|c|}
\hline Level & A & B & C \\
\hline 1 & 8.48 & $11.05^{*}$ & 5.38 \\
\hline 2 & 10.76 & 10.96 & 13.12 \\
\hline 3 & $13.38^{*}$ & 10.61 & $14.12^{*}$ \\
\hline Delta & 4.90 & 0.44 & 8.74 \\
\hline Rank & 2 & 3 & 1 \\
\hline
\end{tabular}

Table 6. Analysis of Variance for $\mathrm{S} / \mathrm{N}$ ratio (before pooling).

\begin{tabular}{|c|c|c|c|c|c|c|}
\hline S* & DoF & SS & V* & $\begin{array}{c}\text { F- } \\
\text { valu } \\
\mathbf{e}\end{array}$ & $\begin{array}{c}\text { Sng* } \\
(\mathbf{Y} / \mathbf{N})\end{array}$ & $\begin{array}{c}\text { PC* } \\
(\%)\end{array}$ \\
\hline $\mathrm{A}$ & 2 & 30.57 & 15.58 & 3.64 & $\mathrm{~N}$ & 16.62 \\
\hline $\mathrm{B}$ & 2 & 2.27 & 1.13 & 0.13 & $\mathrm{~N}$ & 1.23 \\
\hline $\mathrm{C}$ & 2 & 141.1 & 70.52 & 13.8 & $\mathrm{~N}$ & 76.72 \\
\hline $\mathrm{E}^{*}$ & 2 & 9.92 & 4.96 & - & - & 5.39 \\
\hline T* & 8 & 183.8 & - & - & - & 100 \\
\hline Note: Where S, $E$, , Sng and PC signifies source, error, total, variance, \\
significance and percentage contribution.
\end{tabular}

From Table 6, it has been seen that none of the input process parameter in significant. So, the parameter A and C were made significant due to heir higher percentage contribution for MFI as compared to parameter B. In Table 7, the parameter B was pooled and F-value and percentage contribution of parameter $\mathrm{A}$ and $\mathrm{C}$ was calculated again.
Table 7. Analysis of Variance for $\mathrm{S} / \mathrm{N}$ ratio (after pooling).

\begin{tabular}{|c|c|c|c|c|c|c|}
\hline S* & DoF & SS & $\mathbf{V}^{*}$ & $\begin{array}{c}\text { F- } \\
\text { value }\end{array}$ & $\begin{array}{c}\text { Sng* } \\
(\mathbf{Y} / \mathbf{N})\end{array}$ & $\begin{array}{c}\text { PC* } \\
(\%)\end{array}$ \\
\hline $\mathrm{A}$ & 2 & 30.57 & 15.58 & 5.12 & $\mathrm{~N}$ & 16.62 \\
\hline $\mathrm{B}$ & - & - & - & - & - & - \\
\hline $\mathrm{C}$ & 2 & 141.1 & 70.5 & 23.19 & $\mathrm{Y}$ & 76.72 \\
\hline $\mathrm{E}^{*}$ & 4 & 12.2 & 3.04 & - & - & 6.63 \\
\hline $\mathrm{T}^{*}$ & 8 & 183.8 & - & - & - & 100 \\
\hline
\end{tabular}

After pooling, it has been seen from Table 7 that parameter ' $\mathrm{C}$ ' became significant as the calculated $\mathrm{F}$-value at $F_{(2 / 4)}$ is higher than the tabular value (i.e. 6.94) at $95 \%$ confidence level. However, the parameter 'A' still remained in-significant due to its lower F-value. The optimized setting, for MFI, as suggested from response table (Table 5) is at third level of type of filler, first level of proportion of filler and third level of extrusion load. The theoretical value of $\eta$ under the optimum conditions, denoted by $\eta_{\text {opt }}$ could be calculated from Eq. 3:

$$
\begin{gathered}
\eta_{\mathrm{opt}}=\mathrm{m}+\left(\mathrm{m}_{\mathrm{A} 3}-\mathrm{m}\right)+\left(\mathrm{m}_{\mathrm{B} 1}-\mathrm{m}\right)+\left(\mathrm{m}_{\mathrm{C} 3}-\mathrm{m}\right) \\
\eta_{\mathrm{opt}}=16.81 \mathrm{db}
\end{gathered}
$$

Where $\mathrm{m}$ is the overall mean of $\mathrm{S} / \mathrm{N}$ data (i.e. 10.87), $\mathrm{m}_{\mathrm{A} 3}$ is the mean of $\mathrm{S} / \mathrm{N}$ data for factor $\mathrm{A}$ at level 3 and $\mathrm{m}_{\mathrm{B} 1}$ is the mean of $\mathrm{S} / \mathrm{N}$ data for factor $\mathrm{B}$ at level 1, etc. The corresponding value of MFI is given by Eq. 4:

$$
\mathrm{y}_{\mathrm{opt}}^{2}=1 / 10^{-\eta \mathrm{pot} / 10}
$$

$$
\text { So, } \mathrm{y}_{\mathrm{opt}}=6.92 \mathrm{gm} / 10 \mathrm{~min} \text {. }
$$

A confirmatory experiment has been conducted at optimized setting results into MFI of $6.87 \mathrm{gm} / 10 \mathrm{~min}$. As the predicted value is close to the experimental value hence the optimized setting accurate with $95 \%$ confidence level. It has been observed that the MFI of the PMC mixture (at optimized setting) is quiet higher as compared to commercial ABS-P430 material. This led to the discussion that the alternatively fabricated filament of PMC mixture will be difficult to use in the existing FDM setup (at the factory settings). Further at factory settings the higher rate of deposition of extrudate will result with this alternative filament which will tends to bring dimensional errors along with it. However, the same problem can be seen in-term of advantageous as the higher deposition rate can be made adaptable by doing some iteration in the FDM setup interms of the ram speed which will compensate the deposition rate with its movement. 


\section{CONCLUSIONS}

In the present research work, extrusion of the filler reinforced nylon- 6 matrix was carried out by using MFIer. It has been found that type of filler has maximum contribution for MFI due to the thermal conductivity of the fillers. $\mathrm{Al}_{2} \mathrm{O}_{3}$ filler has transferred less amount of heat to its adjoining nylon-6 matrix. Due to this viscous PMC melt was formed, which resulted into reduced MFI value.

Further, with an increase in the extrusion load the MFI of the PMC was also increased. Analysis of variance results highlighted that the percentage contribution of input parameters is: A-16.62\%, B-1.23\% and C-76.72\% at $95 \%$ confidence level.

Presently, no ASTM standard is available for measuring the MFI of hybrid mixture of FDM filament. So, it is suggested to use ASTM-D1238-95 standard particularly for the replacement of ABS based FDM material.

\section{REFERENCES}

1. Bakar, N.S.A., Alkahari, M.R., and Boejang, H., 2010, "Analysis on fused deposition modeling performance", Journal of Zhejiang University Science A, Vol. 11(12), pp. 972-977.
2. Nikzad, M., Masood, S.H., Sbarski, I., and Groh, A., 2009, "A study of melt flow analysis of an abs-iron composite in fused deposition modelling process", Tsinghua Science and Technology, Vol. 14, pp. 29-37.

3. Marcincinova, L.N., and Kuric, I., 2012, "Basic and advanced materials for fused deposition modeling rapid prototyping technology", Manufacturing and Industrial Engineering, Vol. 11, ISSN: 1338-6549.

4. Masood, S.H., and Song, W.Q., 2005, "Thermal characteristics of a new metal/polymer material for FDM rapid prototyping process", Assembly Automation, Vol. 25(4), pp 309-315.

5. Nikzad, M., Masood, S.H., and Sbarski, I., 2011, "Thermo-mechanical properties of a highly filled polymeric composite for Fused Deposition Modeling", Material \& Design, Vol. 32(6), pp. 3448-3456.

6. Ramanath, H.S., Chua, C.K., and Leong, K.F., 2007, "Melt flow behaviour of poly-caprolactone in fused deposition modelling", Journal of Material Science: Materials in Medicine, Vol. 19(7), pp. 2541-2550.

7. Standard Test Method for Melt Flow Rates of Thermoplastics by Extrusion Plastometer, ASTM Designation: D-1238-04. 